University of Louisville

ThinkIR: The University of Louisville's Institutional Repository

Electronic Theses and Dissertations

$5-2001$

\title{
A model for explaining differences in incontinence care seeking (MEDICS) project.
}

Michael Heit 1962-

University of Louisville

Follow this and additional works at: https://ir.library.louisville.edu/etd

\section{Recommended Citation}

Heit, Michael 1962-, "A model for explaining differences in incontinence care seeking (MEDICS) project." (2001). Electronic Theses and Dissertations. Paper 600.

https://doi.org/10.18297/etd/600

This Master's Thesis is brought to you for free and open access by ThinkIR: The University of Louisville's Institutional Repository. It has been accepted for inclusion in Electronic Theses and Dissertations by an authorized administrator of ThinkIR: The University of Louisville's Institutional Repository. This title appears here courtesy of the author, who has retained all other copyrights. For more information, please contact thinkir@louisville.edu. 


\title{
A MODEL FOR EXPLAINING DIFFERENCES IN INCONTINENCE CARE SEEKING (MEDICS) PROJECT
}

\author{
By \\ Michael Heit, M.D. \\ B.S., State University of New York/Binghamton
}

\begin{abstract}
A Thesis
Submitted to the Faculty of the

Graduate School of the University of Louisville

In Partial Fulfillment of the Requirements

For the Degree of

Master of Science

Department of Medicine

University of Louisville Health Science Center

Louisville, Kentucky
\end{abstract}

May 2001 


\title{
A MODEL FOR EXPLAINING DIFFERENCES IN INCONTINENCE CARE
} SEEKING (MEDICS) PROJECT

\author{
By \\ Michael Heit, M.D. \\ B.S., State University of New York/Binghamton
}

A Thesis Approved on

$4 / 30 / 01$

(Date)

by the following Reading Committee:

Thesis Director 


\begin{abstract}
The broad long-term objectives of this research project are to increase the percentage of women who seek care for urinary incontinence. The specific aims of this research project are: 1) Use Lauver's Theory of Care Seeking Behavior to identify predictors of incontinence care seeking for African American and Caucasian women. 2) Determine if previously studied predictors explain incontinence care seeking for AfricanAmerican and Caucasian women, after controlling for predictors in Lauver's Theory of Care Seeking Behavior. 3) Develop and compare theoretical models for explaining differences in incontinence care seeking for African American and Caucasian women. The health relatedness of the project is that our models for incontinence care seeking will guide behavioral interventions which may increase the percentage of women who seek care and reduce any health disparities between African American and Caucasian women.
\end{abstract}


TABLE OF CONTENTS

Page

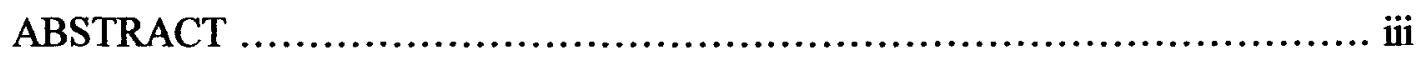

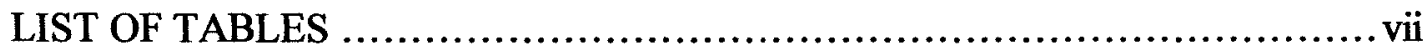

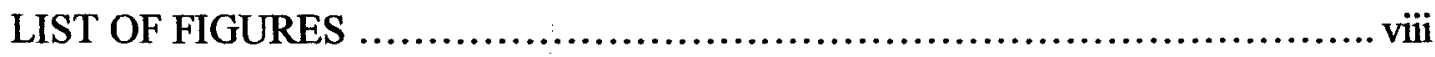

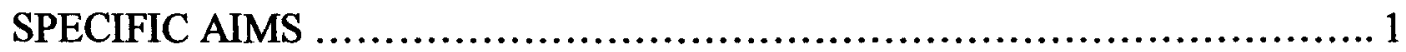

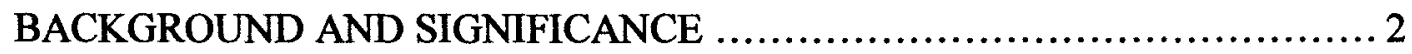

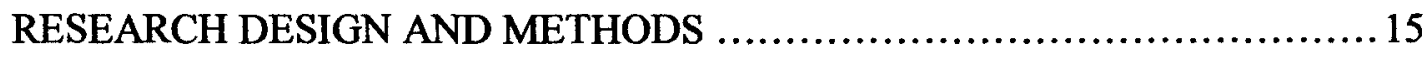

General Overview of Research Design .................................... 15

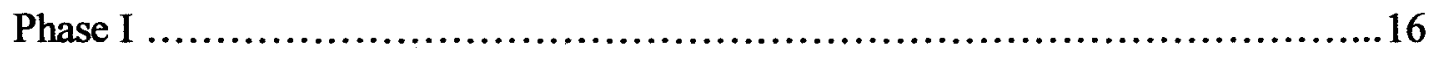

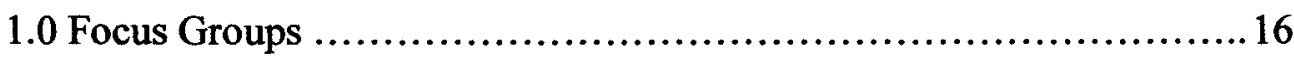

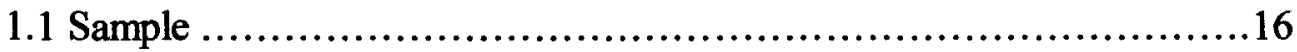

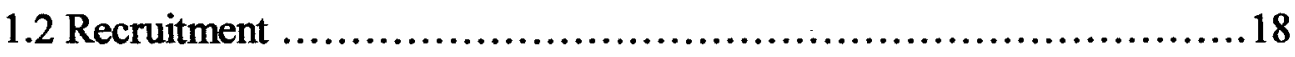

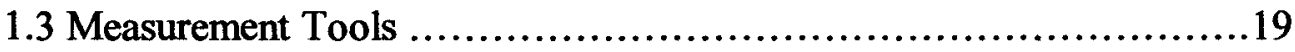

1.3.0 Affect Measurement Tool ................................. 19

1.3.1 Utility Measurement Tool ............................... 19

1.3.2 Facilitator (Barrier) Measurement Tool ......................21

1.3.3 Habit Measurement Tool .................................. 21

1.3.4 Norms Measurement Tool ..................................... 22

1.3.5 Incontinence Care Seeking Measurement Tool ............... 23 
TABLE OF CONTENTS

Page

1.3.6 Symptom Severity Measurement Tool ..................... 24

1.3.7 Health Locus of Control Measurement Tool ...................2 24

1.3.8 SES Measurement Tool ................................. 25

1.3.9 Perceived Health Status Measurement Tool ..................25

1.3.9.1 QOL Measurement Tool ................................26

1.4 Procedure for Second Set of Focus Groups .........................26

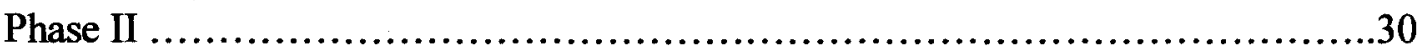

2.0 Pilot Testing .......................................................... 30

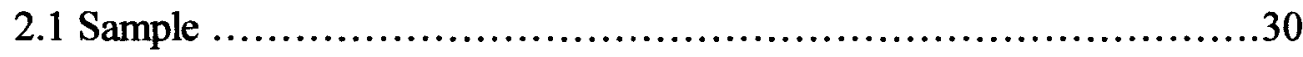

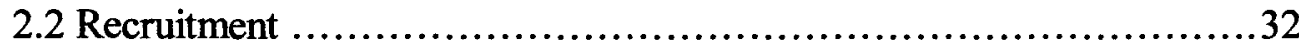

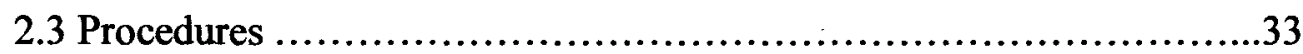

2.4 Statistical Analysis ............................................ 35

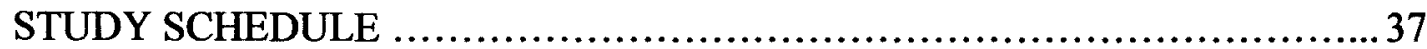

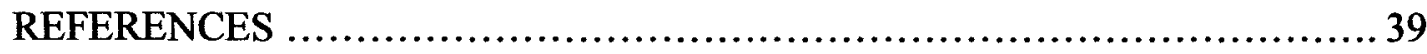

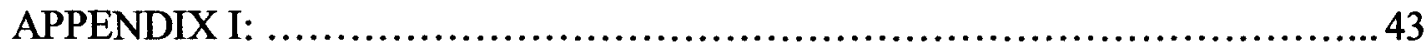

Questionnaire Preamble ............................................. 43

Open-ended Focus Group Questions .................................. 51

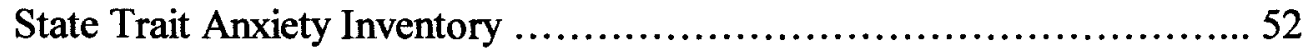




\section{TABLE OF CONTENTS}

\section{Page}

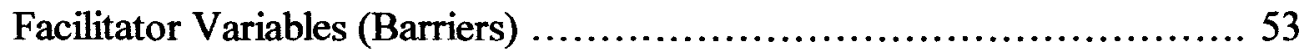

Health Locus of Control ...........................................5

Incontinence Impact Questionnaire (Long Form) ......................56 


\section{LIST OF TABLES}

Tables

1: Number of Participants for Focus Group 1 Cells 17

2: Number of Participants for Focus Group 2 Cells 18

3: Pilot Study Sample Size 31

4: First Year Study Schedule 37

5: Second Year Study Schedule 38 


\section{LIST OF FIGURES}

Figure

Page

1: Lauver's Theory of Care Seeking Behavior 12 


\section{SPECIFIC AIMS}

The broad, long term objectives of this proposal are to increase the percentage of women who seek care for urinary incontinence. The specific aims of this research project are to:

1) Use Lauver's Theory of Care Seeking Behavior to identify predictors of incontinence care seeking for African American and Caucasian women.

a. We will determine if psychosocial variables (affect, utility, norm, and habit) predict care seeking for incontinence directly or by interaction with facilitator (barrier) variables.

2) Determine if previously studied predictors explain incontinence care seeking for African-American and Caucasian women, after controlling for predictors in Lauver's Theory of Care Seeking Behavior.

a. After controlling for psychosocial (affect, utility, norm, and habit), and facilitator (barrier) variables, we will determine if previously studied predictors of care seeking for incontinence add any unique variance.

3) Compare theoretical models for explaining differences in incontinence care seeking for African American and Caucasian women.

a. By examining the differences in predictors for African American and Caucasian incontinence care seeking, our models will guide interventions tailored to meet the needs of each ethnic group. 


\section{BACKGROUND AND SIGNIFICANCE}

Care seeking for urinary incontinence is a poorly understood behavior. Seventy-one percent of continent persons believe that incontinence would have a great deal or fair amount of effect on their lifestyle. If incontinent, $95 \%$ of continent subjects would go to their doctor and only $15 \%$ thought they would feel embarrassed by so doing. In contrast, only $36 \%$ of incontinence sufferers feel that their condition had a great deal or fair amount of effect on their lifestyle. Only $52 \%$ of incontinence sufferers consulted their doctor upon realizing that it was a problem. [Brocklehurst 1993]

The process whereby incontinence sufferers simply adapt and manage their bladder control problem rather than seek treatment has been described as normalization. The rationale behind this normalization process is both complex and multi-dimensional. Health care providers do have some information on predictors of care seeking for incontinence. Epidemiologic studies have identified age as a predictor of care seeking for incontinence. [Jacobsen 1993 \& 1995, Burgio 1994, Rekers 1992, Brocklehurst 1993, Holst 1988, Norton 1998, and Malmsten 1997] Jacobsen found that the proportion of men seeking medical attention for urinary symptoms increased dramatically with age in a linear fashion. After controlling for all potential confounders, age greater than 70 was associated with care seeking for urinary symptoms (OR 4.6, 95\%CI 2.1,10.1). [Jacobsen 1993] In a similar study, Jacobsen found that men age 65 years and older were 2.7 times more likely to have sought care for urinary symptoms in the past year than men less than 
65 years of age $(95 \% \mathrm{CI} 1.1,6.6)$. After controlling for all potential confounding factors, age $>65$ was still associated with care seeking for urinary symptoms. (OR 1.4, 95\%CI 0.5,3.8) [Jacobsen 1995]. Holst found a similar relationship between age and care seeking for incontinence in women. He found that for age, the major differences were for women in the 25 - 34 age group, who were less likely to seek help than those $75+$ years old, who were more likely to seek help. [Holst 1985]

Other studies have found a negative correlation between age and care seeking for incontinence. Rekers found that advancing age was inversely related to consultation with a physician for women aged $35-49,50-64$, and $65-79$ who sought care 34,25 , and $24 \%$ of the time [Rekers 1992]. After controlling for confounders, Burgio found that older individuals were less likely to inform their physician of their problem. [Burgio 1994] Norton found that elderly women comprised the highest proportion of individuals who delayed treatment more than five years [Norton 1988].

Epidemiologic studies have also identified symptom severity as a predictor of care seeking for incontinence. Symptom severity is positively correlated with care seeking for incontinence. [Roberts 1998, Jacobsen 1995, Burgio $1991 \&$ 1994, Holst 1988, Roe 1999, Sandvik 1993, Lagace 1993, Rekers 1992] Roberts found that moderate to severe incontinence was associated with having seen a physician for urinary symptoms in the previous year for men (OR 10.5, 95\% $15.6,19.8$ ) and women (OR 3.8, 95\%CI 2.1,6.7). [Roberts 1998] Jacobsen found that men with moderate to severe symptoms were more likely to have sought health care (OR 3.4, 95\%CI 1.4,8.3). After controlling for all potential confounding factors, men with moderate to severe symptoms were still more likely to have sought care (OR $2.895 \%$ CI 1.1, 7.2). [Jacobsen 1995] Burgio found that 
the frequency and volume of incontinent episodes were positively associated with care seeking for incontinence in women. After controlling for all other potential confounders, patients with daily incontinent episodes were 2 times as likely to seek care for incontinence than in-frequent leakers ( $4 /$ month). When controlling for other factors, patients who wet their outer clothing with each incontinent episode were 1.7 times as likely to seek medical care compared to women who leaked a drop or two [Burgio 1994].

Other previously studied predictor variables of care seeking for incontinence include quality of life [Burgio 1994, Sandvik 1993], perceived mental and medical health [Burgio 1994, Lagro-Janssen 1990], health locus of control [Lagro Janssen 1990], socioeconomic status, level of education [Burgio 1994, Jacobsen 1995], income [Burgio 1994, Jacobsen-1993], and employment [Brocklehurst 1993, Norton 1998].

Burgio found that impairment in activities of daily living (ADL's) especially physical ADL was significantly associated with telling a doctor about incontinence $(p<0.01)$. After controlling for all potential confounding variables, incontinent subjects with impairment in physical ADL were 1.3 times as likely to report symptoms to a doctor. [Burgio 1994]. Similarly, Sandvik showed that incontinent subjects who had consulted a doctor reported more social restrictions than those who had not (45\% vs. 33\%). [Sandvik 1993]

When Lagro-Janssen compared 66 women with recognized incontinence to 140 women with unrecognized incontinence, he found no difference in sociodemographic background (age, marital status, parity, education), psychosocial characteristics (locus of control, social support), perceived health status, or the number of reported chronic diseases. [Lagro-Janssen 1990] 
Jacobsen found that level of education was inversely related to care seeking for men with urinary symptoms. [Jacobsen 1995]. Jacobsen found that the probability of having sought medical care was inversely related to income, in a linear fashion. After controlling for all potential confounders, income less than $\$ 15,000.00$ was associated with care seeking for urinary symptoms (OR 1.7, 95\%CI 0.8,3.6) [Jacobsen 1993]. Burgio found no association between level of education, or level of income, and care seeking for incontinence. Brocklehurst found that on first realizing that incontinence was a problem, sufferers in full time work went to see a doctor. [Brocklehurst 1993]. Norton found that employment status was not significantly associated with delay in care seeking for incontinence. [Norton 1988]

Identifying predictors of care seeking for incontinence has many important implications for sufferers. If clinicians and administrators understood women's reasons for, and barriers to, care seeking for incontinence it would contribute to our ability to bring symptomatic but untreated individuals into the healthcare system. These individuals may benefit from diagnosis and treatment earlier in the disease process, preventing higher levels of morbidity, and loss of quality of life. Existing epidemiologic studies have only identified predictors of care seeking for incontinence in Caucasians limiting the external validity of their findings. How these predictors apply to African Americans is unknown.

While an equal percentage of African Americans and Caucasians suffer from incontinence, their incontinence types differ. Caucasian women suffer from predominantly stress incontinence while African Americans suffer from urge incontinence. [Bump1993] Howard found functional and morphologic differences in the 
urethral sphincteric and support system of nulliparous black and white women. [Howard 2000] Barber found that Caucasian women have a significantly higher incidence of surgery for genuine stress incontinence than African American women. [Barber 2001]. The findings of Bump, Howard and Barber might be explained by differences in incontinence care seeking rather than any anatomic or physiologic differences between African American and Caucasian women.

Previously studied predictors including, socioeconomic status, access to care, and health locus of control differ between African American and Caucasian women. For example, socioeconomically disadvantaged populations are disproportionately made up of minorities. In the United States, in 1990, 11\% of Caucasians, and 32\% of African Americans had incomes below the poverty level. [Frank- Stromberg 1997] Differences in socioeconomic status explain health disparities for the leading causes of death between African Americans and Caucasians. With sociodemographic controls in place, most African American cause specific mortality rates approach those of Caucasians. They are less likely to die from accidents, respiratory diseases, and suicides, and as likely as Caucasians to die from circulatory disease and cancer. [Rogers 1992]

Access to care differs between African Americans and Caucasians. Bailey found that blacks utilize various self-care regimens primarily because of the perceived absence of access to medical care and the cultural trait of individual moral strength. Black Detroit migrants hold a negative attitude about the health care system. This attitude, in turn leads to a tendency not to seek help or to delay seeking. According to the U.S. Department of Health and Human Services, if health professionals recognize cultural variables as they 
apply to various ethnic groups, then health education programs can be tailored more carefully to the meet the needs of minorities. [Bailey 1987]

Finally, health locus of control differs across ethnic groups and has been shown to be associated with health care utilization. Bazargan identified health locus of control scales as the most important predictor of health care utilization by elderly African Americans. A recent National Hospital Ambulatory Medical Care Survey indicated that elderly African Americans display a higher rate of visits to emergency departments and outpatient clinics and lower rates of office based physician visits compared to their Caucasian counterparts. After controlling for demographic variables, higher scores on internal, chance, and powerful other health locus of control scales, enabling characteristics (perceived tangible support, availability of medical doctors) and need characteristics (perceived health status, heart conditions, age problems) predicted emergency room utilization by elderly African Americans. After controlling for demographic variables, higher scores on internal and powerful other health locus of control scales, enabling characteristics (private insurance) and need characteristics (heart conditions, cancer, and limitation of daily activities) predicted hospital admissions for elderly African Americans. Demographic variables (sex, education, living alone), internal and powerful other health locus of control, enabling characteristics (perceived tangible support, availability/accessibility of medical doctors, having Medicaid or private insurance, or residential stability) and need characteristics (HTN, arthritis, breathing problems, stomach, ear, teeth and blood circulation problems, stroke and cancer) predicted physician visits for elderly African Americans. Elderly African Americans 
with higher levels of education, who were male, and who lived alone, reported a greater number of physician visits.

The identification of perceived accessibility and availability of medical services and health locus of control as influential determinants of health care utilization among elderly African Americans provides a basis for designing interventions to modify utilization behaviors within that community. [Bazargan 1998]

Theories designed to explain health behaviors act as roadmaps or guidelines to help synthesize a body of research more easily, to understand a behavior more fully, and propose ways in which an intervention may be most effective. [Lauver 1992a] In our study, we will use Lauver's Theory of Care Seeking Behavior to identify predictors of care seeking for incontinence in African American and Caucasian women.

Lauver's Theory of Care Seeking Behavior is based on Triandis's Theory of Behavior, which is comprehensive, powerful, and sensitive to differences among persons of differing socioeconomic status. Variables from Triandis' Theory have been shown to explain 33 to $66 \%$ of the variance in health behaviors or intentions such as mammography use and exercise. [Lauver 1992a] Lauver's Theory of Care Seeking Behavior, states that the probability of engaging in a health behavior is a function of psychosocial variables (affect, utility, habits and norm) and facilitating (barrier) variables regarding the behavior. The Theory of Care Seeking Behavior differs in part from Triandis' Theory by not including physiologic arousal as a predictor variable for explaining health behavior. Affect, which is included in Lauver's model, is assumed to be an indicator of arousal making its inclusion unnecessary. [Lauver 1992a] 
According to the Theory of Care Seeking Behavior, affect refers to feelings associated with care seeking such as anxiety about receiving a serious diagnosis, or embarrassment about an examination. No studies address affect as a predictor of care seeking for incontinence. However, reasons for not seeking incontinence care include fear of surgery [Rekers 1992, Reymert 1994, Norton1998] and embarrassment over discussing symptoms with physicians [Reymert 1994, Norton 1998, Goldstein 1992, Rizk 1997].

Affective variables such as anxiety, fear, and embarrassment have predicted care seeking for other health related problems. Anxiety interacted with having identified a health practitioner to explain care seeking for women with breast cancer symptoms [Lauver 1994]. For women without a practitioner, higher anxiety was associated with less delay. For women with a practitioner, the relationship between anxiety and care seeking was not significant.

Expectations refer to beliefs about the perceived likelihood of either good or bad outcomes from seeking care. Beliefs about outcomes of care seeking behavior are distinct from beliefs about a specific illness. Value refers to the importance of each expectation of care seeking. Utility reflects the overall worth of care seeking and is measured as the sum of the products of each expectation and its corresponding value score. An association between utility beliefs and care seeking for incontinence has not been studied. However, reasons for not seeking continence care include negative ideas about treatment possibilities [Rekers 1992], having the idea that other people could not help them [Rekers 1992, Reymert 1994], and low expectation of benefits from treatment [Holst 1988, Goldstein 1992, Rizk 1997]. 
Utility was found to have a significant positive association with an intention to seek care for breast cancer symptoms [Lauver 1992b]. In another study, asymptomatic women with greater utility beliefs had greater intentions to seek mammograms as recommended [Lauver 1997].

Norms include social norms which reflect others' beliefs about care seeking, personal norms which reflect one's own beliefs about the morally correct behavior regarding care seeking and interpersonal agreement reflecting a promise with another to engage in care seeking. Burgio found that as the number of close friends with whom subjects felt at ease and could discuss private matters increased, the more likely they were to tell a doctor about their incontinence. Exchanging health information with friends also tended to be associated with reporting incontinence. [Burgio 1994]. Reasons for not seeking continence care provided by sufferers include not wanting to talk about it, not knowing whom to talk to, and having the idea that other people could not help [Rekers 1992].

Compared to women with weaker social norms, women with stronger social norms about mammography had twice the odds of having a recent mammogram or intention to seek a mammogram as recommended. [Lauver 1997].

Habit refers to how one usually acts when one has symptoms, which reflects past experience with care seeking behavior. Burgio found three health habits associated with care seeking for incontinence including, following a low fat diet, following a low salt diet, and having a smoke detector in the home. The importance of watching one's weight was related to reporting incontinence. Patients who felt that regular physical exams were important were more likely to report incontinence. Patients who saw their physicians for 
annual physical exams were 2.5 times more likely to report incontinence than patients who saw their physicians less than every three years. Burgio suggests that this effect may be explained by more contact with health care providers who may inquire about specific conditions, increased contact and familiarity with providers who make patients more comfortable discussing incontinence, or having more natural opportunities to discuss one's problems. [Burgio 1994]

Habit is associated with intention to seek care and promptness for actual care seeking for breast cancer symptoms [Lauver 1994, 1992b]. Women with preventive habits had 4.8 times greater odds of adhering to mammogram recommendations than women without such habits. Women with preventive habits had twice the odds of having a recent mammogram than those without such habits. They were also more likely to intend to seek mammograms as recommended [Lauver 1997].

Finally, facilitators are specific, objective, external conditions that enable one to seek care. Facilitating conditions are opposite to those that would present obstacles to seeking care. Therefore, measures of facilitating conditions may reflect barriers to care and vice versa. [Lauver 1992a] Jacobsen found that men without insurance were more likely to have sought medical care for urinary symptoms [Jacobsen 1993]. Burgio found no association between health care seeking for incontinence and distance from the health care provider measured in miles. [Burgio 1994]. According to incontinence sufferers, reasons for not consulting a doctor included, did not know a doctor well enough [Reymert 1994], worry about costs [Goldstein 1992], and male physician [Rizk 1997].

Facilitator (barriers) variables have been associated with care seeking directly and in interaction with psychosocial variables. Identifying a health care practitioner who they 
usually saw for health problems interacted with anxiety to explain care seeking for breast cancer symptoms. For women without a practitioner, higher anxiety was associated with less delay. For women with a practitioner, anxiety was not associated with care seeking [Lauver 1994]

According to Lauver's theory, psychosocial variables (affect, utility (expectations $\mathrm{x}$ values), norms and habits) may directly explain care-seeking behavior. Psychosocial variables can also interact with facilitator (barrier) variables to explain care seeking behavior. Clinical and demographic variables such as age, race, and socioeconomic status are external to the theory because any influences of clinical and demographic factors should be captured by the salient psychosocial and facilitating (barrier) variables. [Lauver 1992a]

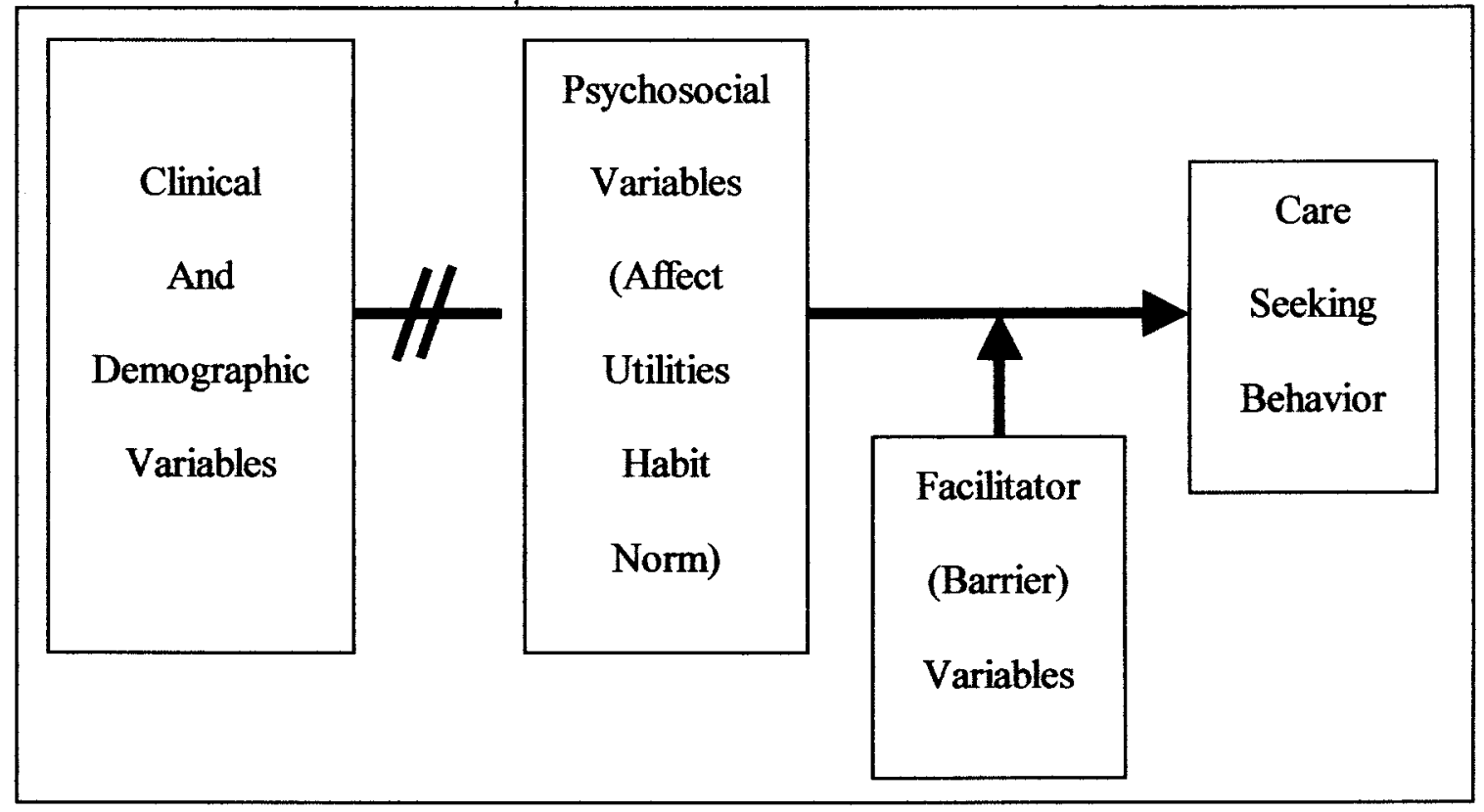

Figure 1. Lauver's Theory of Care Seeking Behavior

Lauver's Theory of Care Seeking Behavior has provided the framework for studying whether psychosocial (affect, utility, norm and habit) and facilitator (barrier) predictors of care seeking differ between African Americans and Caucasians. After controlling for 
education, financial coverage for healthcare, and family history of breast disease, utility and habit were positively related to intentions to seek care for breast cancer symptoms. Psychosocial variables alone were responsible for explaining 34\% of the variance. Interactions of both utility and norms with race, significantly explained intention, and increased the explained variance by $4 \%$. The positive influence of utility on intention was stronger for Caucasians than African Americans while the positive influence of social norm was significant only for Caucasians. [Lauver 1992b].

In a second study, utility and habit explained care seeking directly, and accounted for $10 \%$ of the variance. Habit was associated with promptness, while utility beliefs were associated with delay in care seeking. Adding an interaction term of anxiety by identified practitioner explained an additional $6 \%$ of the variance. After controlling for psychosocial and facilitator (barrier) variables, optimism and having a friend with breast cancer explained an additional $8 \%$. Race had neither direct nor interactive effects on care seeking. [Lauver 1994]

In summary, Lauver's Theory of Care Seeking Behavior can provide the framework for identifying predictors of incontinence care seeking for African American and Caucasian women. By controlling for the variables in Lauver's Theory of Care Seeking Behavior, we will determine if previously studied predictors of incontinence care seeking add any unique variance. Differences in predictor variables between African American and Caucasian women will be examined. By studying the differences in predictors of incontinence care seeking for African American and Caucasian women, we expect to identify areas where behavioral interventions may increase the percentage of African American and Caucasian women who seek care for incontinence. Therefore, our study 
will meet the broad national health goals set forth in Healthy People 2010, which includes increasing the years of healthy life, reducing health disparities, and achieving access to preventative services for all Americans. [Healthy People 2010]. 


\section{RESEARCH DESIGN AND METHODS}

\section{General Overview of Research Design}

In phase I of our research protocol, we will use focus groups to adapt Lauver's Theory of Care Seeking Behavior for the clinical problem of urinary incontinence. We will modify her affect, utility, facilitator (barrier), habit, and norms measurement tools to adapt them for the clinical problem of urinary incontinence. We will add established measurement tools for previously studied predictors of incontinence care seeking including, symptom severity, health locus of control, socioeconomic status, perceived health status and quality of life. We will conduct additional focus groups to determine the clarity, comprehensiveness and acceptability of each measurement tool for African American and Caucasian women. At the completion of phase I, we will have a survey instrument capable of measuring the previously studied predictors of incontinence care seeking and variables in Lauver's Theory of Care Seeking Behavior in African American and Caucasian women. In phase II, we will use the survey instrument to conduct a computer assisted telephone interview (CATI) and identify predictors of care seeking for incontinence in African American and Caucasian women. At the completion of phase II, we will have pilot data to develop a nationwide CATI using a random digit dialing sampling technique. 


\section{Phase I}

\section{ADAPTING LAUVER'S THOERY OF CARE SEEKING BEHAVIOR FOR THE CLINICAL PROBLEM OF URINARY INCONTINENCE.}

\subsection{Focus groups}

The objective of the first set of focus groups are to modify each of Lauver's measurement tools (affect, utility, facilitator (barrier), habit, and norms) in the Theory of Care Seeking Behavior for the clinical problem of urinary incontinence. We will add established measurement tools for previously studied predictors of incontinence care seeking including, symptom severity, health locus of control, socioeconomic status, perceived health status and quality of life. Our second set of focus groups will be used to determine the clarity, comprehensiveness and acceptability of each measurement tool for African American and Caucasian women.

\subsection{Sample}

For our first set, we will conduct eight focus groups to meet our objectives. We will consider race (Caucasian, African American) and socioeconomic status (low and high) as the critical characteristics for selecting our focus group participants. (Table 1) Socioeconomic status will be calculated based on the methodology of Green. (see Section 1.3.8) A nonprobability sample of 80 continent women between the ages of 35 and 80 will be recruited to participate. To modify the utility measurement tool it is important that we recruit continent women because it eliminates the potential for confounding based 
on symptom severity. Incontinent women will be used to modify the affect, norms, habit, and facilitator (barrier) measurement tools.

Table 1

Number of participants for focus group 1 cells

\begin{tabular}{|c|c|c|c|c|}
\hline Focus Group & \multicolumn{4}{|c|}{ Race/Continence Status } \\
\hline $\begin{array}{c}\text { Socioeconomic } \\
\text { Status }\end{array}$ & $\begin{array}{c}\text { Continent } \\
\text { Caucasians }\end{array}$ & $\begin{array}{c}\text { Incontinent } \\
\text { Caucasians }\end{array}$ & $\begin{array}{c}\text { Continent } \\
\text { African } \\
\text { Americans }\end{array}$ & $\begin{array}{c}\text { Incontinent } \\
\text { African } \\
\text { American }\end{array}$ \\
\hline Low & 10 & 10 & 10 & 10 \\
\hline High & 10 & 10 & 10 & 10 \\
\hline
\end{tabular}

To complete our survey instrument, we will add established measurement tools for previously studied predictors of incontinence care seeking to our modified affect, utility, facilitator (barrier), habit, and norms measurement tools. Our second set of focus groups will be used to determine the clarity, comprehensiveness and acceptability of all the measurement tools in our survey instrument for African American and Caucasian women. For our second set, we will conduct four focus groups to meet our objectives. Again we will consider race (Caucasian, African American) and socioeconomic status (low and high) as the critical characteristics for selecting our focus group participants.

(Table 1) A nonprobability sample of 40 incontinent women between the ages of 35 and 80 will be recruited to participate. 
Table 2

Number of participants for focus group 2 cells

\begin{tabular}{|c|c|c|}
\hline Focus Group & \multicolumn{2}{|c|}{ Race } \\
\hline $\begin{array}{c}\text { Socioeconomic } \\
\text { Status }\end{array}$ & Caucasian & $\begin{array}{c}\text { African } \\
\text { American }\end{array}$ \\
\hline Low & 10 & 10 \\
\hline High & 10 & 10 \\
\hline
\end{tabular}

\subsection{Recruitment}

To meet the focus group cell requirements, the University of Louisville's Survey Research Center will recruit focus group participants from their own phone banks at their facility. To recruit 10 individuals for each focus group cell, they will recruit 15 individuals per cell, as we expect a $20-35 \%$ no show rate for committed participants. A convenience sampling technique will be used to recruit participants for our focus groups, which will enable us to contact a large number of candidates in a relatively short period of time and at a minimal cost. Generalizing our findings to the United States population is not the objective of this study phase, which overcomes the limitations of this sampling technique. Telephone calls will be placed to invite the potential participants to the planned focus groups, and to inform the potential candidate of the purpose, sponsor, date, time, and place of the focus group sessions. We will also provide information on the amount of financial incentives, and number of meals and refreshments provided. The Survey Research Center will send a letter of confirmation to accepting guests detailing meeting specifics. The Survey Research Center will make follow-up telephone calls to accepting guests one to two days prior to the focus group meeting. 
The University of Louisville's Survey Research Center will schedule and moderate all focus group sessions. A female moderator will begin with an introduction including a reference to the use of recording equipment, a brief overview of the subject matter to be covered and an explanation of the discussion rules. The site will provide video and audio taping equipment for archiving the proceedings. The proceedings will be monitored onsite by the principal investigator and qualitative sociologist.

\subsection{Measurement tools}

\subsubsection{Affect variable}

For the purpose of this study, affect will be measured by a modified version of the State-Trait Anxiety Inventory. This inventory will be modified by substituting the adjective "embarrassed" for shaky since embarrassment is more appropriate for our clinical situation [Lauver 1999]. Trait anxiety, defined as "relatively stable individual differences in anxiety proneness" will be measured by a 20 item, 4 point Likert scale questionnaire which is written at a fifth grade level. The internal consistency of the trait anxiety scale is 0.89 for working adult females ages $50-69$. Test-retest reliability coefficients of 0.73 to 0.86 to 0.92 have been reported for the trait subscale whose construct validity was determined by comparing like subjects under stressful and nonstressful conditions. [Spielberger 1983]

\subsubsection{Utility Measurement tool}

Proponents of the Theory of Reasoned Action maintain that preliminary research is needed to develop valid measures of expectations and values that are salient to care seeking for incontinence. If such expectations were described and if valid and reliable measures of these expectations were developed, then the relationship of utility beliefs to 
actual care seeking for incontinence could be examined more accurately. [Lauver 1993] Because participants are continent and therefore not care seeking for incontinence, women will be asked to imagine that they had just developed a problem with uncontrollable urine loss. They will be asked, focused open-ended questions about their expectations regarding outcomes, advantages and disadvantages of either seeking incontinence care promptly or adopting a wait and see approach. (See appendix). A themed analysis will include an 1) independent review of the interview data for commonly reported themes in response to focused questions, 2) independent generation of themes for expected outcomes, advantages and disadvantages of seeking prompt care or adopting a wait and see approach, 3) collaborative identification of categories of responses that represent the newly generated themes. [Lauver 1993] From this preliminary research, two questionnaires on the perceived likelihood of good or bad outcomes of incontinence care seeking (expectations) and the importance of that outcome (value) will be developed. Patients will be asked to assess the likelihood (probability) of a specific outcome of incontinence care seeking from 0 (not at all likely) to 100 (definitely). Patients will be asked to assess the importance of the specific outcome from 0 (not at all important) to 100 (extremely important). The products of each matched expectation and value question will be summed to obtain a utility score for incontinence care seeking.

In a study designed to assess whether the influences of affect, utility, norm, and habit on intention to seek care for breast cancer symptoms were conditional upon race, the internal consistency coefficient for the expectation and value questions were 0.71 to 0.78 and 0.68 to 0.73 , respectively. [Lauver $1992 \mathrm{~b}$ ] 


\subsubsection{Facilitator (Barrier) measurement tool}

For the purpose of this study, facilitators (barriers) to incontinence care seeking will be assessed using a modification of Melnyk's Barriers Scale. This measurement tool was developed to operationalize the concept of barriers as the consumer's perceptions of cost or obstacles to care [Melnyk 1990]. This scale has been used by Lauver to measure the facilitator (barrier) variable in the Theory of Care Seeking Behavior [Lauver 1994]. Modifications of the scale for the clinical problem of urinary incontinence were based on a review of reasons for not seeking medical care for incontinence in the medical literature. [Rekers 1992, Holst 1988, Sandvik 1993, Reymert 1994, Goldstein 1992, and Rizk 1997]. This modified measurement tool cations will be tested for Patients will be asked to rate the degree to which barrier items affected their seeking medical care for incontinence on a 4-point Likert scale ranging form 0 (none) to 4 (greatly). Higher barrier scores will reflect fewer facilitators of care seeking. In a study comparing care seeking for breast cancer symptoms in Caucasians and African American Women, Melynk's Barriers Scale had an internal consistency coefficient of 0.70 [Lauver 1994]

\subsubsection{Habit variable}

Focus group participants will be asked whether they usually seek care for symptoms in general, and how they usually act when they have symptoms of urinary urgency, frequency, and dysuria suggesting a urinary tract infection. Response options include, did not seek care, wait to see if symptom persists then sought care, or sought care right away. Reactions to urinary tract infection symptomatology are chosen as representative of habits and their ability to predict care seeking for incontinence because this disorder is prevalent in women, treatable, rarely life threatening, and a common transient cause of 
incontinence. To calculate a habit score, the values for the two responses will be added together. Higher scores reflect greater tendencies to seek prompt symptomatic care.

Because preventive behaviors such as following a low fat diet, following a low salt diet, or having a smoke detector in their home has been found to predict care seeking for incontinence, [Burgio 1994], study participants will be asked if they engage in such behaviors. They will respond on a 4-point Likert Scale, 0 (never) to 3 (always) for the first two questions and yes/no for the third. A preventive behavior score will be calculated by adding the results of the first two questions. The response to the third question will be handled, separately in the analysis.

Because frequent physicals exam predict prompt care seeking for incontinence [Burgio 1994], study participants will be asked how frequently they are seen for physical exams. Responses will range from greater than or equal to once a month to less than every three years.

We will determine if each measure of habit (habit score, preventive behavior score, use of smoke detectors, and frequency of physical exams) is an independent predictor of care seeking for incontinence, within our theoretical framework.

\subsubsection{Norms measurement tool}

From our first set of focus group sessions, we will identify influential people that participants rely on for healthcare guidance (i.e. female friend, spouse, male friend, mother, father, other female relative, doctor or nurse). To measure social norm, participants will be asked to identify the people they have discussed their symptoms with and how important this significant other thinks they should seek care for incontinence right away. Some study participants will not have discussed their symptoms with a 
significant other. These participants will be asked their perception of how important a significant other might think they should seek care for incontinence right away. Evaluating an incontinent person's perceptions of social norms, prevents missing data for patients who have not discussed their symptoms. Study participant's responses will be scored on a Likert Scale ranging from 0 (not at all necessary) to 3 (extremely necessary). Mean social norm scores will be obtained by adding the response score for each significant other and dividing by the number of influential people they rely on for healthcare guidance. The internal consistency coefficients of the social norm questions range from 0.84 to 0.88 . [Lauver $1992 \mathrm{~b}$ ]

\subsubsection{Incontinence care seeking measurement tool}

Incontinence care seeking behavior is our dependent variable of interest and will be determined as follows. Study participants will be asked if they have sought care for uncontrollable urine leakage in the past 12 months. According to Cleary, the validity of self reported physician utilization is acceptable. In their study, the average difference between reported and actual utilization in the previous year was only 0.05 visits. Advancing age, frequent medical utilization, and membership in a prepaid health insurance plan were related to underreporting, while belief in regular checkups, health status, and demoralization were related to over reporting. They concluded by stating that it is possible to generate accurate aggregate self-report utilization data provided that interviewers make every effort to reduce error by using detailed probes and providing memory aids. [Cleary 1984]. Interviewers will ask respondents to relate care-seeking episodes to important life events such as anniversaries, and holidays. Participants who respond affirmatively will be considered to have sought care. 


\subsubsection{Symptom severity measurement tool}

For the purpose of our study, symptom severity will be measured by self-report. Participants will characterize their urine leakage frequency as: $1=$ less than once a month, $2=\mathrm{a}$ few times a month, $3=\mathrm{a}$ few times a week, and $4=$ every day and/or night. They will also report the amount of urine leakage per episode as; $1=$ drops, $2=$ small splashes, and $3=$ more. The incontinence severity index will be calculated as the product of the frequency scale and the volume of urine leakage present with scores ranging from $1-12$. The construct validity of this four-level severity index has been established by comparison with pad weighing tests with a correlation coefficient of 0.54 . [Sandvik 1993]

\subsubsection{Health locus of control measurement tool}

Health locus of control measures people's beliefs that their health is or is not determined by their behavior. The internal health locus of control assesses the extent to which individuals believe they are responsible for their health, the extent to which individuals can avoid behavior that increases the risk of disease, and the extent to which they should play an active role in coping with their illness. The chance health locus of control focuses on the extent to which persons believe their health or sickness to be a function of external forces such as luck, accident, good fortune and so on. The powerful others health locus of control assesses the extent to which individuals believe that powerful others, particularly physicians, nurses and other health professionals are responsible for their health and illness. [Wallston 1978]. We will establish the health locus of control for each study participant by having them complete all three 12-item questionnaires. Each scale has been shown to be internally consistent with Cronbach's alpha coefficients ranging from 0.830 to 0.859 . Correlations in the predicted direction 
between health locus of control scores and health status, provided evidence for their construct validity.

\subsubsection{Socioeconomic status measurement tool}

For the purpose of our study, income, occupation, and education data will be combined to create a socioeconomic status score based on the method of Green [Green 1970]. According to Green, the main purpose of socioeconomic scores is to partition variance in health behavior explained by socioeconomic factors so that other contributing variables such as knowledge and attitudes can be analyzed independently. To optimize prediction of nine preventive health behaviors, Green combined education, income and occupational scores weighted differently for white and nonwhite persons. When sensitive data on income is unavailable, a two-factor socioeconomic index is calculated without a significant loss in predictive value. Scores range from 30 to 85 , with 58 , established as the cut-off between low and high socioeconomic categories.

\subsubsection{Perceived Health Status measurement tool}

The Health Perceptions Questionnaire will be used to assess subjective perceptions of health, rather than objective measures of health status, because they predict utilization of care. This 33 item survey instrument records perceptions of past, present and future health, resistance to illness, and attitudes toward sickness. It has been used as an outcome measurement in the Rand Health Insurance Experiment and as a predictor of care [McDowell 1996]. Cronbach's alpha and test retest reliability coefficients for the six subscales range from 0.59 to 0.91 and 0.50 to 0.67 , respectively. Construct validity has been established for the current health and prior health subscales by comparing them to 
disability days, number of chronic problems, pain level and psychological well being, with correlation coefficients ranging from 0.30 to 0.60

\subsubsection{Quality of life measurement tool}

The psychosocial impact of urinary incontinence on activities of daily living will be assessed with the disease specific Incontinence Impact Questionnaire [Uebersax 1995]. Cronbach's alpha coefficients for the physical activity, travel, social relationships and stress symptoms subscales are $0.87,0.87,0.90$, and 0.90 , respectively. Criterion validity was established by comparing Incontinence Impact Questionnaire scores with number of incontinent episodes with correlation coefficients of 0.46 . Secondly, focus group participants will be asked to identify influential people they rely on for guidance (norms), and specific, objective external conditions that enable (facilitators) or obstruct (barriers) them from seeking care. Answers to these open ended questions will be used to modify the established norm and facilitator (barrier) measurement tools used in Lauver's Theory of Care Seeking Behavior.

\subsection{Procedure for second set of focus groups}

Using the entire survey instrument, female interviewers will conduct in-person interviews with each focus group participant. In-person interviews will be used in this phase of the study so we can get immediate feedback on the entire survey instrument, prior to its final revision. Focus group participants will be asked to imagine that the interviews are being conducted by phone. When all of the participants have completed the survey they will be asked open-ended questions designed to determine the clarity, comprehensiveness and acceptability of the entire survey instrument. All of the 
proceedings will be videotaped and monitored onsite by the principal investigator and qualitative sociologist.

We will adapt the entire survey instrument to socioeconomically disadvantaged (SED) populations because we will test the hypotheses that race and socioeconomic status predict care seeking for incontinence. SED disadvantaged populations are disproportionately made up of minorities and of persons with limited social experiences. SED study participants may have impaired language skills including a limited vocabulary, which can limit their viewpoint to their own personal experience and may not comprehend the rationale for questions. SED participants may have difficulty categorizing data and may not be capable of distinguishing between nuances of terms or distinguishing between spectrums of options. Each of these areas of difficulty can jeopardize the reliability of our survey instrument. We will overcome these limitations by reducing the survey's literacy level, making individual word changes, widening the response options, being aware of socially desirable answers and shortening the survey instrument. [Frank-Stromberg 1997]

Most studies have found that people tend to read three to five grade levels below the last grade completed, which makes an assessment of the participants reading abilities, and the literacy level of the survey instrument imperative. The reading level of the focus group participants will be tested using the reading subset of the Wide Range Achievement Test (WRAT), which takes five minutes to administer. The SMOG Readability Formula is a common tool for assessing instrument readability, and is accurate to within 1.5 to 2 grade levels. By matching the lowest reading level of the 
focus group participants study participants to the literacy level of the survey instrument we will maximize its comprehension. [Frank-Stromberg 1997]

We will limit our survey to thirty minutes for fear of jeopardizing our response rate due to a reluctance to complete the instrument. A patterned series of responses (automatic, unidirectional set of responses) and fatigue or disinterest can jeopardize the reliability of the survey instrument. Approaches to minimizing the risk of patterned responses will be used, such as changing the order of fixed responses from question to question, and using questions that vary substantially in terms of wording or length.

SED participants have a greater tendency to respond to questions with socially desirable answers. The validity of our study may be jeopardized if participants unreliably state that they have sought incontinence care after admitting that they have uncontrollable urine loss because it's the socially acceptable thing to do. To reduce the chance for introducing bias, we will direct the focus of the study away from the decision to use health care [Cameron 1993], and separate measures of predictor variables in the Theory of Incontinence Care Seeking Behavior from care seeking variables in the computer assisted telephone (CATI) interviews. [Lauver 1994] To maximize the reliability of responses, questions will be asked in the following order, 1) questions involving personal reflections with similar response options (4 and 5 point Likert scale responses). The purpose of these questions will be to increase the ease of responses; 2) questions involving objective phenomena which are clinically oriented such as the date of symptom onset and contacting the healthcare system, habits, clinical history, and present symptomatology; 3) questions that are least likely to be influenced by other responses and are somewhat sensitive such as demographic factors. 
At the completion of phase I of our study, we will have a survey instrument capable of measuring the previously studied predictors of incontinence care seeking and variables in Lauver's Theory of Care Seeking Behavior. 


\section{Phase II}

\section{PILOT TEST OUR SURVEY INSTRUMENT TO IDENTIFY PREDICTORS OF CARE SEEKING FOR INCONTINENCE IN AFRICAN AMERICAN AND CAUCASIAN WOMEN.}

\subsection{Pilot testing}

The primary objective of the pilot test is to obtain data on the predictive ability of variables on our survey instrument in preparation for a nationwide computer assisted telephone interview (CATI) using a random digit dialing sampling technique. We will also obtain accurate estimates of the time required to complete the instrument and the cost of data collection. During the pilot test, we expect that interviewers will gain experience and confidence in working with the survey instrument and typical study participant mixes.

\subsection{Sample}

For the pilot study, the Survey Research Center will recruit a nonprobability sample of United States community dwelling women aged $35-80$ whose incontinence prevalence is expected to be $26.5 \%$ (range 14.4-32.0\%). [Rekers et al 1992] The Survey Research Center will recruit participants from purchased lists derived from nationwide purchasing patterns, using a snowball sampling technique. A snowball sampling technique is beneficial when it is difficult to identify potential respondents. We will rely on initial respondents to provide access to other incontinent women during the recruitment period. Because we will recruit a nonprobability sample of incontinent 
women we will be unable to generalize our findings to United States community dwelling incontinent women between the ages of 35 and 80 . However, the primary objective of the pilot test is to obtain data in preparation for a nationwide CATI using a random digit dialing sampling technique. The probability sample obtained with a random digit dialing technique can be used to generalize findings to our working population.

By choosing a confidence interval of $95 \%$, we will need a minimum total sample size of 196 incontinent women to obtain a 7\% margin of error around our proportion estimates for each predictor variable. [Rea 1997] To fill each cell with an equal number of study participants, it will be necessary to over sample African-Americans to maintain our minimum sample size of 196 participants. We will reduce the number of Caucasians sampled accordingly. To prevent skewing of the data towards the smaller strata, we will employ a weighting procedure to compare predictors of care seeking for incontinence for African American and Caucasian women.

Table 3

Pilot Study Sample Size

\begin{tabular}{cccccc}
\hline Race/Ethnicity & $\begin{array}{c}\% \\
\text { U.S. of } \\
\text { Pop }\end{array}$ & $\begin{array}{c}\text { Prop } \\
\text { Sample } \\
\text { Population }\end{array}$ & $\begin{array}{c}\text { SES } \\
\text { Stratum }\end{array}$ & $\begin{array}{c}\text { Prop } \\
\text { Sample }\end{array}$ & $\begin{array}{c}\text { Disprop } \\
\text { Sample } \\
\text { Population }\end{array}$ \\
\hline Caucasian & $73 \%$ & 175 & Low & 87 & 60 \\
& \multirow{2}{*}{ High } & 88 & 60 \\
\hline African & \multirow{2}{*}{$12 \%$} & 29 & Low & 16 & 60 \\
American & & & High & 13 & 60 \\
\hline Total & $85 \%$ & 204 & & 240 & 240 \\
\hline
\end{tabular}




\subsection{Recruitment}

The director of the Survey Research Center will provide female interviewers with a sample list of telephone numbers to contact potential study candidates by phone in the early evening (6:00PM to 9:00PM) and on the the weekends (noon to 9:00PM). These times provide interviewers with greater opportunities to reach working adult household members. An institutional review board approved preamble (see Appendix) will be read to all potential study candidates, which will identify the researchers conducting the study, introduce the purpose of the study, provide an estimate of the time required to complete the survey, assure confidentiality, and obtain informed consent.

After obtaining informed consent, the female interviewer will ask a screening question to determine if the candidate meets the inclusion criteria for the study. In their epidemiologic survey, Diokno defined urinary incontinence as any uncontrolled urine loss in the prior 12 months without regard to severity. [Diokno 1986] For the purpose of our study, study candidates will be asked, "without regard to severity, have you experienced any involuntary, accidental or uncontrollable urine leakage over the past 12 months". Candidates who respond affirmatively will be considered incontinent, and asked to participate. Contacts who respond negatively will be thanked for their time and excluded from participation.

Efforts to enhance response rates will be used to limit the time needed to obtain the sample sizes needed for the pilot study. If the interviewer encounters a busy signal, they will call again in thirty minutes. If the line is busy, the call will be placed again the next day. If the call the next day is busy, the interviewer will call again in thirty minutes. If the line is still busy, the interviewer will try calling again on another day at a 
completely different time from the previous attempts. If the line is still busy the number will be classified as a non-response. Recruitment will continue until the sample size requirements have been met.

\subsection{Procedures}

At the Survey Research Center, female interviewers will use the 12 computer assisted telephone interview (CATI) stations to collect survey data. Compared to hard copy telephone interviewing, computer assisted telephone interviewing has several advantages. These include facilitation of complex question branching, random assignment of interviewers to telephone numbers which reduces interviewer bias, randomization of the location or sequence of selected questions which eliminates any order effects, immediate identification of invalid responses, on-line monitoring of interviews by supervisors, and immediate input of completed interviews into raw data files. [Harlow 1985, Marcus 1987]

Despite these advantages, telephone surveys have several limitations, which could affect the reliability of our results. Income is considerably lower and minority groups are over represented in non-telephone households. Therefore, telephone surveys are subject to non-telephone coverage bias. However, in his review of the 1980 Health Interview Survey, Marcus found only small differences in selected demographic characteristics when comparing non-telephone to telephone households. In only 3 cases did estimates differ by more than $1 \%$ and in no cases did estimates differ by more than $2 \%$. [Marcus 1986].

Compared to in-person interviews, telephone surveys tend to have $10-20 \%$ lower response rates. To determine the impact of non-response bias, two researchers compared 
sociodemographic characteristics in initial participants to nonrespondents who were recontacted, and persuaded to participate. The two groups differed in occupation, education, income, race, country of ancestry, and housing status. Despite these sociodemographic differences, none of the differences in the estimated population parameters exceeded 2\%. [Marcus 1986]

While non-telephone coverage and non-response bias may not individually produce large systematic errors in estimating population parameters, their combined effect may be great. However, areas that have low telephone coverage and non-response rates are the same areas that have high non-response rates to in-person interviews. These similarities effectively eliminate the differential advantage of this sampling technique. Our study is designed to minimize any systematic errors in estimating population parameters from non-telephone coverage and non-response bias. In our pilot study, a nonprobability sample of incontinent women will be recruited until each of our racia/socioeconomic cells contains 60 respondents, despite the methodologic inconveniences of less telephone coverage and higher non-response rates.

In reporting sensitive topics, such as incontinence status and income, Marcus reviewed several studies which support his conclusion that little to no difference exist between telephone and in-person interviewing techniques. Obtaining income information by telephone survey may be subject to primacy bias (order effect) where respondents may disproportionately select one of the earlier income response options from a list. To overcome primacy bias, our CATI survey stations will randomly alternate income response options from low to high and high to low. Within each racial/socioeconomic 
cell in our pilot study, a more accurate estimation of income will be obtained by averaging results from the two sets of response options. [Marcus 1986].

Three strategies (commitment, instructions, and feedback) developed by the University of Michigan will be used to minimize underreporting in telephone surveys. These strategies were found to increase reports of acute and chronic symptoms, bed days, work-loss days, restricted activity, and physician visits. [Marcus 1986].

1. Commitment - In our questionnaire preamble, we will ask contacts to verbally commit to a pledge for hard work during the interview

2. Instructions - In our questionnaire preamble, we will provide improved instructions explaining what is expected, and how respondents can produce complete and accurate answers.

3. Feedback - Using a script to standardize feedback, interviewers will be trained to systematically reinforce positive, and discourage negative or nontask oriented respondent behavior.

After all the telephone surveys for the pilot testing have been completed, data stored in the system will be downloaded into SPSS for Windows v10.0 for analysis by our statistician.

\subsection{Statistical Analysis}

1) To account for the disproportionate sampling used in our protocol, weights will be applied to the data for each race/socioeconomic stratum.

2) Bivariate Analysis: In both African American and Caucasian women, those subjects who have sought care for incontinence will be compared to those who have not, in terms of previously studied predictors and psychosocial and facilitator (barrier) 
variables in Lauver's Theory of Care Seeking Behavior. Student's t-test will be used for continuous variables that appear to follow a normal distribution and the Mann-WhitneyWilcoxon test will be used for those that do not follow a normal distribution. Fisher's exact test will be used for categorical variables.

Multivariate Analysis: In both African American and Caucasian women, a stepwise logistic regression will be run to determine if the previously studied predictors of care seeking for incontinence add any unique variance after controlling for psychosocial and facilitator (barrier) variables. At step one the explanatory power of psychosocial (affect, utility, norm, habit) and facilitator (barrier) variables on care seeking for incontinence will be determined, and only those that have a significant effect will be retained. At step two, the interaction effects of the retained psychosocial and facilitator variables on care seeking for incontinence will be determined. Interaction terms will be computed by multiplying the scores of interacting variables together. Only those interaction effects that are statistically significant will be retained. At step three, previously studied predictors that have a bivariate association with care seeking for incontinence in our racially diverse female population, will be entered to determine if they independently predict care seeking for incontinence.

ANCOVA - A two factor (race, care seeking) analysis of covariance will be used to determine if predictors of incontinence care seeking differ between African American and Caucasian women. 


\section{STUDY SCHEDULES}

Table 4

First Year Study Schedule

\begin{tabular}{|c|c|c|c|c|c|c|c|c|c|c|c|c|}
\hline & \multicolumn{12}{|c|}{ First year of study (mos) } \\
\hline Planned Activity & 1 & 2 & 3 & 4 & 5 & 6 & 7 & 8 & 9 & 10 & 11 & 12 \\
\hline Plan focus group & $\mathrm{X}$ & $\mathbf{x}$ & & & & & & & & & & \\
\hline $\begin{array}{l}\text { Recruit focus group participants } \\
\left(1^{\text {st }} \text { set }\right)\end{array}$ & & $\mathrm{X}$ & $\mathbf{X}$ & $\mathbf{X}$ & $\mathrm{X}$ & & & & & & & \\
\hline Conduct 8 focus groups & & & & $\mathbf{X}$ & $\mathrm{X}$ & $\mathbf{X}$ & $\mathbf{X}$ & & & & & \\
\hline $\begin{array}{l}\text { Modify measurement tools for } \\
\text { Lauver's Theory of Care } \\
\text { Seeking Behavior }\end{array}$ & & & & & & & & $\mathrm{X}$ & $\mathrm{X}$ & & & \\
\hline $\begin{array}{l}\text { Recruit focus group participants } \\
\left(2^{\text {nd }} \text { set }\right)\end{array}$ & & & & & & & & $\mathrm{X}$ & $\mathbf{X}$ & & & \\
\hline Conduct 4 focus group & & & & & & & & & & $\mathbf{X}$ & $\mathbf{X}$ & \\
\hline $\begin{array}{l}\text { Revise the measurement tools } \\
\text { for predicting incontinence } \\
\text { Care Seeking Behavior }\end{array}$ & & & & & & & & & & & & $\mathrm{X}$ \\
\hline
\end{tabular}


Table 5

Second Year Study Schedule

\begin{tabular}{|l|c|c|c|c|c|c|c|c|c|c|c|c|}
\hline & \multicolumn{7}{|c|}{ Second year of study (mos) } \\
\hline Planned Activity & 1 & 2 & 3 & 4 & 5 & 6 & 7 & 8 & 9 & 10 & 11 & 12 \\
\hline $\begin{array}{l}\text { Program CATI stations with } \\
\text { survey instrument (Phase 3) }\end{array}$ & $\mathrm{X}$ & & & & & & & & & & & \\
\hline Recruit and train female \\
interviewers
\end{tabular}




\section{REFERENCES}

Bailey, Eric. Sociocultural Factors and Health Care-Seeking Behavior among Black Americans. J of the National Med Assoc 79: 389-392. 1987.

Barber M, Gustilo-Ashby T, Weidner A, Datta S, Myers E. Racial Differences in the Incidence of Surgery For Genuine Stress Incontinence, United States 1997. Abstract from 2001 Society of Gynecologic Surgeons Annual Clinical Meeting. P42

Bazargan, Mohsen, Bazargan, Shahrzad, and Baker, Richard. Emergency Department Utilization, Hospital Admissions, and Physician Visits Among Elderly African American Persons. The Gerontologist 38: 1, 25-36. 1998

Brocklehurst JC. Urinary Incontinence in the Community - Analysis of a MORI poll, Br Med J, 306: 832-834, 1993

Burgio KL, Matthews KA, Engel BT. Prevalence, Incidence and Correlates of Urinary Incontinence in Healthy, Middle-Aged Women. J Urol, 146: 1255-1259, 1991

Burgio KL, Ives, Diane G, Locher, Julie, Arena, Vincent, and Kuller, Lewis. Treatment Seeking for Urinary Incontinence in Older Adults. JAGS 42: 208-212. 1994.

Bump R,. Racial Comparisons and Contrasts in Urinary Incontinence and Pelvic Organ Prolapse. Obstet Gynecol 81: 4121-425, 1993

Cameron, Linda, Leventhal, Elaine, and Leventhal, Howard. Symptom Representations and Affect as Determinants of Care Seeking in a Community-Dwelling, Adult Sample Population. Health Psychology 12: 3, 171-179. 1993.

Cleary, Paul D and Jette, Alan M. The Validity of Self-reported Physician Utilization Measures. Med Care 22: 9, 796-803. 1984

Diokno AC, Brock BM, Brown MB, Herzog AR. Prevalence of Urinary Incontinence and Other Urological Symptoms in the Noninstitutionalized elderly. J Urol, 136: 1022-1025, 1986.

Frank-Stromberg, Marilyn and Olsen, Sharon J. Instruments for Clinical Health-Care Research. $2^{\text {nd }}$ edition, Boston: Jones and Bartlett Publishers, 1992

Goldstein, Marianne, Hawthorne, Mary E., Engelberg, Sandie, McDowell, B. Joan, and Burgio KL. Urinary Incontinence: Why People Do Not Seek Help. Journal of Gerontological Nursing 18: 4, 15-20. 1992. 
Green, Lawrence W. Manual for Scoring Socioeconomic Status for Research on Health Behavior. Public Health Reports 85: 9, 815-827. 1970.

Harlow, Bernard, Rosenthal, Jeanne, Ziegler, Regina. A Comparison of ComputerAssisted and Hard Copy Telephone Interviewing. Am J of Epid. 122: 335-340, 1985

Holst, Kristen and Wilson PD. The Prevalence Of Female Urinary Incontinence And Reasons For Not Seeking Treatment. NZ Med J 101: 756-758. 1988.

Howard D, Delancey J, Tunn R, Ashton-Miller, J. Racial Differences in the Structure and Function of the Stress Urinary Continence Mechanism. Obstet Gynecol 95: 713-717, 2000

Jacobsen, SJ, Guess, HA, Panser, L, Girman, CJ, Chute, CG, Oesterling, JE, and Lieber, MM. A Population-Based Study Of Health Care-Seeking Behavior For Treatment Of Urinary Symptoms - The Olmstead County Study Of Urinary Symptoms And Health Status Among Men. Arch Fam Med 2: 729-735. 1993.

Jacobsen, SJ, Chute, CG, Girman, CJ, Oesterling, JE, Guess, HA, Lieber, MM, and Panser, L. Do Prostate Size and urinary Flow Rates predict Health Care-Seeking Behavior for Urinary Symptoms in Men? Urology 45: 1, 64-69. 1995.

Jacobson, A. Health-Care-Seeking Behavior: Implications for the Primary Care Physician. Psychosomatic Medicine 57: 48-49. 1995.

Lagace EA, Hansen W, Hickner JM. Prevalence and Severity of Urinary Incontinence in Ambulatory Adults; an UPRNet Study. J Fam Pract 36:610-614. 1993

Lagro-Janssen, Toine, Smits, Anton, and Van Weel, Chris. Women With Urinary Incontinence: Self-Perceived Worries And General Practitioners' Knowledge Of Problem. British Journal of General Practice 40: 331-334. 1990.

Lauver, Diane. A Theory Of Care-Seeking Behavior. Journal of Nursing Scholarship 24: 4, 281-288. 1992a.

Lauver, Diane. Psychosocial Variables, Race And Intention To Seek Care For Breast Cancer Symptoms. Nursing Research 41: 4, 236-241. $1992 \mathrm{~b}$.

Lauver, Diane and Angerame, Mary. Women's Expectations About Seeking Care For Breast Cancer Symptoms. Oncology Nursing Forum 20: 3, 519-525. 1993.

Lauver, Diane. Care-Seeking Behavior with Breast Cancer Symptoms in Caucasian and African-American Women. Research in Nursing \& Health 17: 421-431. 1994.

Lauver, Diane, Nabholz, Sharon, Scott, Kay, and Tak, Y. Testing Theoretical Explanations of Mammography Use. Nursing Research 46: 1, 32-39. 1997. 
Lauver DR, Kane J, Bodden J, McNeel J, Smith L. Engagement in Breast Cancer Screening Behaviors. ONF. 26: 545-554. 1999

Malmsten, Ulf, Milsom, Ian, Molander, Ulla, and Norlen, Lars. Urinary Incontinence And Lower Urinary Tract Symptoms: An Epidemiological Study Of Men Aged 45 To 99 Years. J Urology 158: 1733-1737. 1997.

Marcus, Alfred, Crane, Lori. Telephone Surveys in Public Health Research. Med Care, 24: 97-112, 1986

McCullock Melnyk, Kay Ann. Barriers to Care: Operationalizing the Variable. Nursing Research 39: 2, 108-112. 1990.

McDowell I, Newell C. Measuring Health. Second edition. New York: Oxford University Press, 1996.

Norton PA, MacDonald, LD, Sedgwick, PM, and Stanton SL. Distress And Delay Associated With Urinary Incontinence, Frequency, And Urgency In Women. BMJ 297: 1187-1189, 1988.

Rea L, Parker R. Designing and Conducting Survey Research; A Comprehensive Guide. 2nd Edition ed. San Francisco: Jossey-Bass Inc., 1997.

Rekers, H, Drogendijk, AC, Valkenburg, H, and Riphagen, F. Urinary Incontinence In Women From 35 To 79 Years Of Age: Prevalence And Consequences. European J of Ob/Gyn \& Reprod Biology 43: 229-234, 1992.

Reymert, Jannike and Hunskaar, Steinar. Why Do Only A Minority Of Perimenopausal Women With Urinary Incontinence Consult A Doctor? Scand J Prim Health Care 12: 180-183, 1994.

Rizk, DEE, Shaheen, H, Dunn, TE, and Hassan, MY. The Prevalence And Determinants Of Health Care-Seeking Behavior For Urinary Incontinence In United Arab Emirates Women. Int Urogynecol J 10: 160-165, 1999.

Roberts, Rosebud, Jacobsen, SJ, Rhodes, Thomas, Reilly, W. Terence, Girman, CJ, Talley, Nicholas, and Lieber, MM. Urinary Incontinence In A Community-Based Cohort: Prevalence And Healthcare-Seeking. JAGS 46: 467-472. 1998.

Roe, Brenda, Doll, Helen, and Wilson, Kate. Help Seeking Behaviour And Health And Social Services Utilization By People Suffering From Urinary Incontinence. Int J of Nursing Studies 36: 245-253. 1999.

Rogers RG. Living and Dying in the U.S.A.: Sociodemographic Determinants of Death Among Blacks and Whites. Demography. 29:287-303. 1992 
Sandvik H, Seim A, Vanvik A, Hunskaar S. A Severity Index for Epidemiological Surveys of Female Urinary Incontinence: Comparison with 48-Hour Pad-Weighing Tests. Neurourol Urodynam: 19: 137-145, 2000.

Sandvik, Hogne, Kveine, Eldri, and Hunskaar, Steinar. Female Urinary Incontinence Psychosocial Impact, Self Care and Consultations. Scand J Caring Sci 7: 53-56. 1993.

Spielberger, Charles D. State Trait Anxiety Inventory (Form Y). 1983. Mind Garden.

Uebersax J, Wyman J, Shumaker S, McClish D, Fantl A. Short Forms to Assess Life Quality and Symptom Distress for Urinary Incontinence in Women: The Incontinence Impact Questionnaire and the Urogenital Distress Inventory. Neurourol Urodynam, 14: 131-139,1995.

Wallston, Kenneth A., Wallston, Barbara S, and DeVellis, Robert. Development of the Multidimensional Health Locus of Control (MHLC) Scales. Health Education Monographs 6: 2, 160-170. 1978.

Wrightson, KJ and Wardle, J. Cultural Variation In Health Locus Of Control. Ethnicity \& Health 2: 12, 13-20. 1997. 


\section{APPENDIX I}

\section{Questionnaire Preamble}

You are being invited to participate in a research study. The purpose of this study is to determine the reasons why women ask for help for health related medical problems. This study is being conducted by Dr. Michael Heit and is sponsored by the Department of Obstetrics and Gynecology at the University of Louisville.

Please remember that your participation in this study is voluntary. If you agree to participate, you will be asked to respond to a series of questions by phone. The survey should take approximately $\mathbf{3 0}$ minutes to complete. You may decline to answer any question. There are no risks or benefits to you for participation; however, the knowledge gained may benefit others because of doctors can figure out why women ask for help they can develop plans to treat all women who are in need.

Your completed survey will be stored at the Urban Studies Institute at the University of Louisville. Individuals from the Department of Obstetrics and Gynecology and the University Human Studies Committee may inspect these records. In all other respects, however, the data will be held in confidence to the extent permitted by law. Should the data be published, your identity will not be disclosed.

By completing this questionnaire, you are indicating that all your present questions have been answered in language you can understand. All future questions will be treated in the same manner. You may refuse to participate without being subject to any penalty or losing any benefits to which you are otherwise entitled. If you have any questions about this study, you may contact the principal investigator at 502-629-2442. If you have any questions about your rights as a research subject, you can contact the University Human Studies Committee at (502)-852-5188. The committee has reviewed this study.

By completing this questionnaire, you are agreeing to participate. If you are willing to participate we ask that you pledge to work hard during the interview and answer each question to the best of your ability.

Do you pledge to work hard during the interview and answer each question to the best of your ability?

No

Yes 
In this interview you will be asked a series of questions pertaining to why women ask for help for health related medical problems. The types of questions I will ask you differ in that they can be answered in many ways. Some questions have no choices for answers so we ask you to fill in the blank. Some questions can be answered with a simple yes or no. Some questions have multiple choices, where we ask you to select the best option.

Multiple-choice questions can differ based on the type of answers that are possible. For instance, in some questions we will ask you to grade your response such as never, rarely, sometimes, often, or always. In some questions we will simply ask you to choose from a set of answers that do not involve grading such as blue, orange, pink, or yellow. Finally, none of the questions will have more than one answer.

\section{Continence Care Seeking Behavior}

Have you sought care for uncontrollable urine loss in the past 12 months?

Yes No

How many days have elapsed between the time you first noticed symptoms of uncontrollable urine loss and either made an appointment or visited a physician for an evaluation? days

\section{Continence Status}

Have you had a problem with uncontrollable urine loss over the past 12 months? Yes No

\section{Demographic Variables}

Age

How old are you? years old

What is your date of birth?

Race

Which race do you consider yourself belonging to?

Caucasian African American Asian/Pacific Islander Hispanic Other 
Medical Care Coverage

What type of medical care coverage/insurance do you have?

None

Medicaid

Medicare with or without supplement

Private 


\section{Income}

Which category best describes your yearly family income level before taxes?
(81) $\$ 50,000$ or more
(72) $\$ 25,000$ to $\$ 49,999$
(64) $\$ 15,000$ to $\$ 24,999$
(58) $\$ 12,000$ to $\$ 14,999$
(57) $\$ 10,000$ to $\$ 11,999$
(54) $\$ 9,000$ to $\$ 9,999$
(52) — $\$ 8,000$ to $\$ 8,999$
(50) $\$ 7,000$ to $\$ 7,999$
(48) _ $\$ 6,000$ to $\$ 6,999$
(46) — $\$ 5,000$ to $\$ 5,999$
(44) — $\$ 4,000$ to $\$ 4,999$
(42) $\$ 3,500$ to $\$ 3,999$
(40) $\$ 3,000$ to $\$ 3,499$
(39) $\$ 2,500$ to $\$ 2,999$
(37) $\$ 2,000$ to $\$ 2,499$
(35) $\$ 1,500$ to $\$ 1,999$
(33) $\$ 1,000$ to $\$ 1,499$
(28) Less than $\$ 1,000$

\section{Education}

What education level have you completed? Elementary school 1-3 years` high school

(53) High school graduate

(62) $1-3$ years' college

(69) 4 or more years' college

\section{Occupation}

What is the job of the main moneymaker in your family?

SES (nonwhite $)=(0.36 \mathrm{X}$ Education score $)+(0.42 \mathrm{X}$ Income score $)+(0.25 \mathrm{X}$ Occupation score $)$ SES (white $)=(0.59 \times$ Education score $)+(0.27 \times$ Income score $)+(0.25 \times$ Occupation score $)$ Range of scores 30 to 85

Low SES $=30$ to 57

High SES $=58$ to 85 


\section{Clinical Factors}

Severity of Incontinence

How often do you experience urinary leakage?

Less than once a month

A few times a month

A few times a week

Every day and/or night

How much urine do you lose each time?

Drops

Small splashes

More

Multiplying the results of questions 1 and 2 creates the severity index

In the three level severity index, responses to the second question are first aggregated into drops (1) and more (2), and then multiplied with the frequency, resulting in the following index values (1-8):

$1-2=$ slight

3-4 = moderate

6-8 = severe

The four-level severity index is based on the following index values (1-12)

1-2 = slight

3-6 = moderate

8-9 = severe

$12=$ very severe

\section{Incontinence Duration?}

When did you first notice symptoms of uncontrollable urine leakage? month year

Duration is calculated as difference in time (days) between date of interview and date of symptom onset

\section{Symptom change}

How would you describe you uncontrollable urine leakage now compared to when you first noticed it?

Better No change Worse

Friends with incontinence 
Do you have any close friends with uncontrollable urine leakage?

Y Yes __ No

Family history of urinary incontinence

Do you have any close relatives with uncontrollable urine leakage?

Yes No

Pad usage

How many pads do wear in a day to protect your clothes from your uncontrollable urine leakage? pads/day

Marital status

Are you presently married?

Yes No

\section{Norms}

Have you discussed seeking care for uncontrollable urine loss with a:

Female friend

Yes No

If yes, how did they feel about you seeking care for uncontrollable urine loss right away? not at all necessary rarely necessary necessary extremely necessary

Husband Yes No

If yes, how did they feel about you seeking care for uncontrollable urine loss right away? not at all necessary rarely necessary necessary extremely necessary

\section{Mother}

Yes No

If yes, how did they feel about you seeking care for uncontrollable urine loss right away? not at all necessary rarely necessary necessary extremely necessary 
Other female relative

Who? Yes _ No,

If yes, how did they feel about you seeking care for uncontrollable urine loss right away? not at all necessary rarely necessary necessary extremely necessary

Usual health care practitioner/doctor Yes No

If yes, how did they feel about you seeking care for uncontrollable urine loss right away? not at all necessary rarely necessary necessary extremely

Habit

How do you usually act when faced with health related problems or symptoms?

Do not seek care

Wait to see if health related problems or symptoms persist and then seek care Seek care right away

How do you usually act when faced with urgency, frequency, and burning with urination suggestive of a urinary tract infection?

Do not seek care

Wait to see if health related problems or symptoms persist and then seek care Seek care right away

How important is it for you to engage or practice in preventative health care behaviors such as;

Regular exercise program

Not important

Somewhat important

Important

Extremely important

Following a low fat, low salt diet

Not important

Somewhat important

Important

Extremely important 
Having a smoke detector in the home

Not important

Somewhat important

Important

Extremely important

Watching your weight

Not important

Somewhat important

Important

Extremely important

How often do you see a physician for a physical exam $<3$ years - never

Every 2-3 years

Annually

$\geq$ Once a month 
Open-ended focus group questions to obtain salient outcomes for incontinence care seeking behavior. Used to develop valid measures of utility (Expectations X Values) of incontinence care seeking

1. Let's say that you chose to take a wait-and-see approach to your uncontrollable urine leakage. What do you think would happen over the next few months as a result of this approach? (Clarify as necessary: What would you expect as outcomes of this approach?)

2. Let's say that you chose to see a health practitioner immediately. What do you think would happen as a result of this approach? (Clarify as necessary: What would you expect as outcomes of this approach?)

3. What do you see as the good aspects or advantages, if any, of taking a wait-andsee approach to uncontrollable urine leakage?

4. What do you see as the bad aspects or disadvantages, if any, of taking a wait-andsee approach?

5. What do you see as the good aspects or advantages, if any, of seeing a health professional right away for uncontrollable urine leakage?

6. What do you see as the bad aspects of disadvantages, if any, of seeing a heath professional right away?

Expectations (Perceived likelihood of good or bad outcomes of continence care seeking)

0 100

not at all likely definitely

Values (How important each good or bad outcome of continence care seeking is to you)

0

not at all likely

definitely 


\section{State Trait Anxiety Inventory}

\begin{tabular}{|c|c|c|c|}
\hline 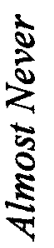 & 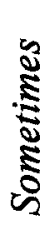 & $\underbrace{\mathbb{s}}_{0}$ & 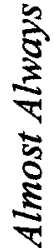 \\
\hline 1 & 2 & 2 & 4 \\
\hline
\end{tabular}

1. I feel pleasant

2. I feel nervous and restless

3. I feel satisfied with myself

4. I wish I could be as happy as others seem to be

5. I feel like a failure

6. I feel rested

7. I am "calm, cool, and collected"

8. I feel that difficulties are piling up so that I cannot overcome them

9. I worry too much over something that really doesn't matter

10. I am happy

11. I have disturbing thoughts

12. I lack self-oonfidence

13. I feel secure

14. I make decisions easily

15. I feel inadequate

16. I am content

17. Some unimportant thought runs through my mind and bothers me

18. I take disappointments so keenly that I can't put them out of my mind

19. I am a steady person

20. I get in a state of tension or turmoil as I think over my recent concerns and interests 


\section{Facilitator Variables (Barriers)}

\section{Provider-consumer relationship}

Does not having a physician who would check your uncontrollable urine loss, affect you from seeking medical help

Does not knowing how to get an appointment with a physician who would check your uncontrollable urine loss, affect you from seeking medical help

\section{Cost}

Does long delays before insurance repays your out-of -pocket expenses, affect you from seeking medical help for my uncontrollable urine loss

Does finding your insurance too complicated to figure out, affect your from seeking medical help for your uncontrollable urine loss Does having no medical insurance, affect you from seeking medical help for your uncontrollable urine loss

If the cost of having your uncontrollable urine loss checked is too high, would this affect you from seeking medical help

If the cost of lost wages from having your uncontrollable urine loss checked is too high, would this affect you from seeking medical help

\section{Accessibility}

I have no transportation to the office or clinic where I would have my uncontrollable urine loss checked

The cost of transportation to the office or clinic where I would have my uncontrollable urine loss checked is too high

The office or clinic where I would have my uncontrollable urine loss checked is too far away

\section{Inconvemience}

The waiting time in the physician's office is too long to have my uncontrollable urine loss checked

Appointments to have my uncontrollable urine loss checked have to be scheduled too far ahead

The office or clinic where I would have my uncontrollable urine loss checked has limited office hours which conflict with my schedule

An inability to arrange childcare prevents me from seeking care for my uncontrollable urine loss 


\section{Health Locus of Control}

Intermal Health Locus of Control (IHLC)

If I get sick, it is my own behavior which determines how soon I get well again

I am in control of my own health

When I get sick I am to blame

The main thing which affects my health is what I myself do

If I take care of myself, I can avoid illness

If I take the right actions, I can stay healthy

If I become sick, I have the power to make myself well again

I am directly responsible for my health

Whatever goes wrong with my health is my own fault

My physical well-being depends on how well I take care of myself

When I feel ill, I know it is because I have not been taking care of myself properly

I can pretty much stay healthy by taking good care of myself

Powerful Others Health Locus of Control (PHLC)

Having regular contact with my physician is the best way for me to avoid illness

Whenever I don't feel well, I should consult a medically trained professional

My family has a lot to do with my becoming sick or staying healthy

Health professionals control my health

When I recover from an illness, it's usually because other people (for example, doctors, nurses, family, friends) have been taking good care of me

Regarding my health, I can only do what my doctor tells me to do

If I see an excellent doctor regularly, I am less likely to have health problems

I can only maintain my health by consulting health professionals

Other people play a big part in whether I stay healthy or become sick

Health professionals keep me healthy

The type of care I receive from other people is what is responsible for how well I recover from an illness

Following doctor's orders to the letter is the best way for me to stay healthy 


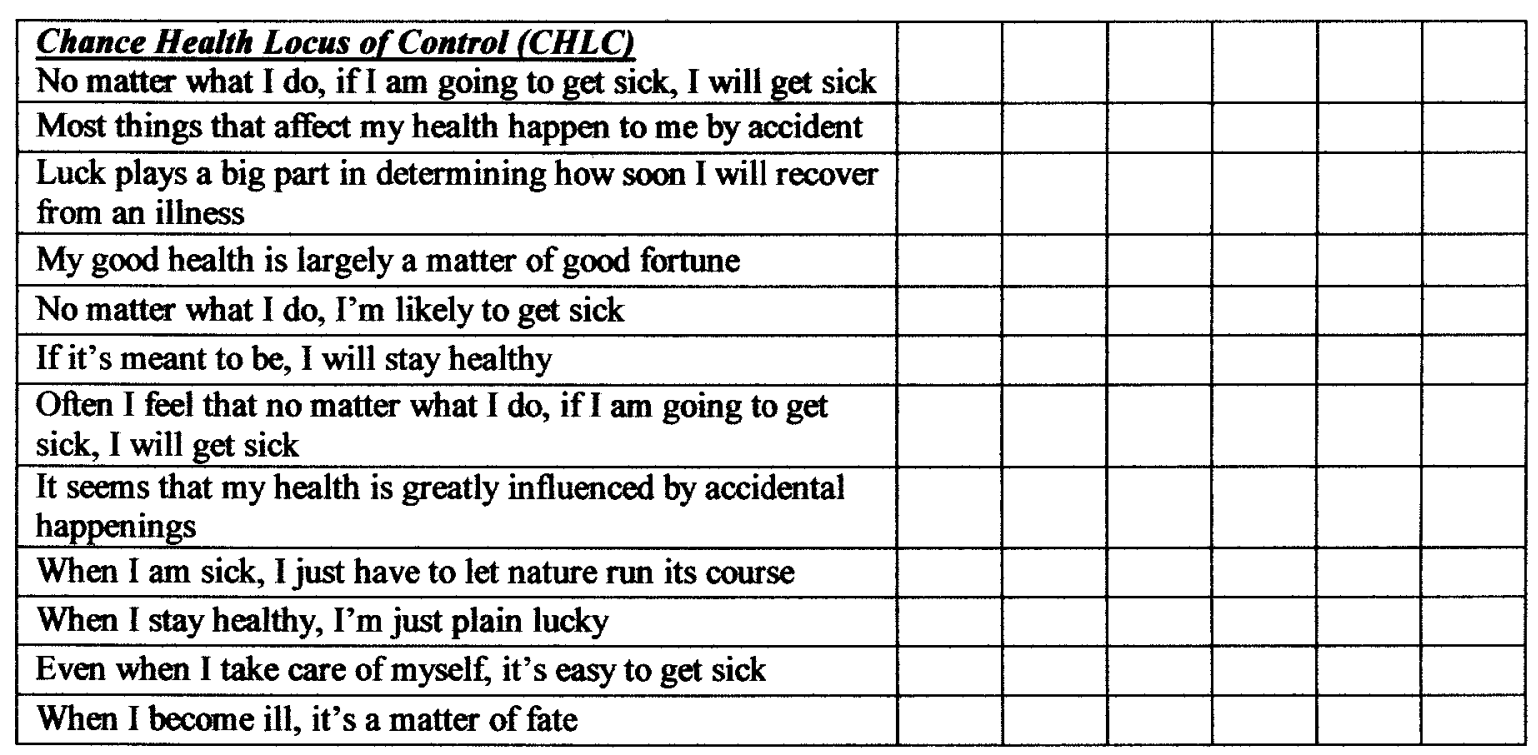


Incontinence Impact Questionnaire - Long form

Item response levels are $0=$ not at all, $1=$ slightly, $2=$ moderately, and $3=$ greatly. $P A=$ physical activity; $T=$ travel;

$\mathrm{SR}=$ social/relationships; $\mathrm{EH}=$ emotional health.

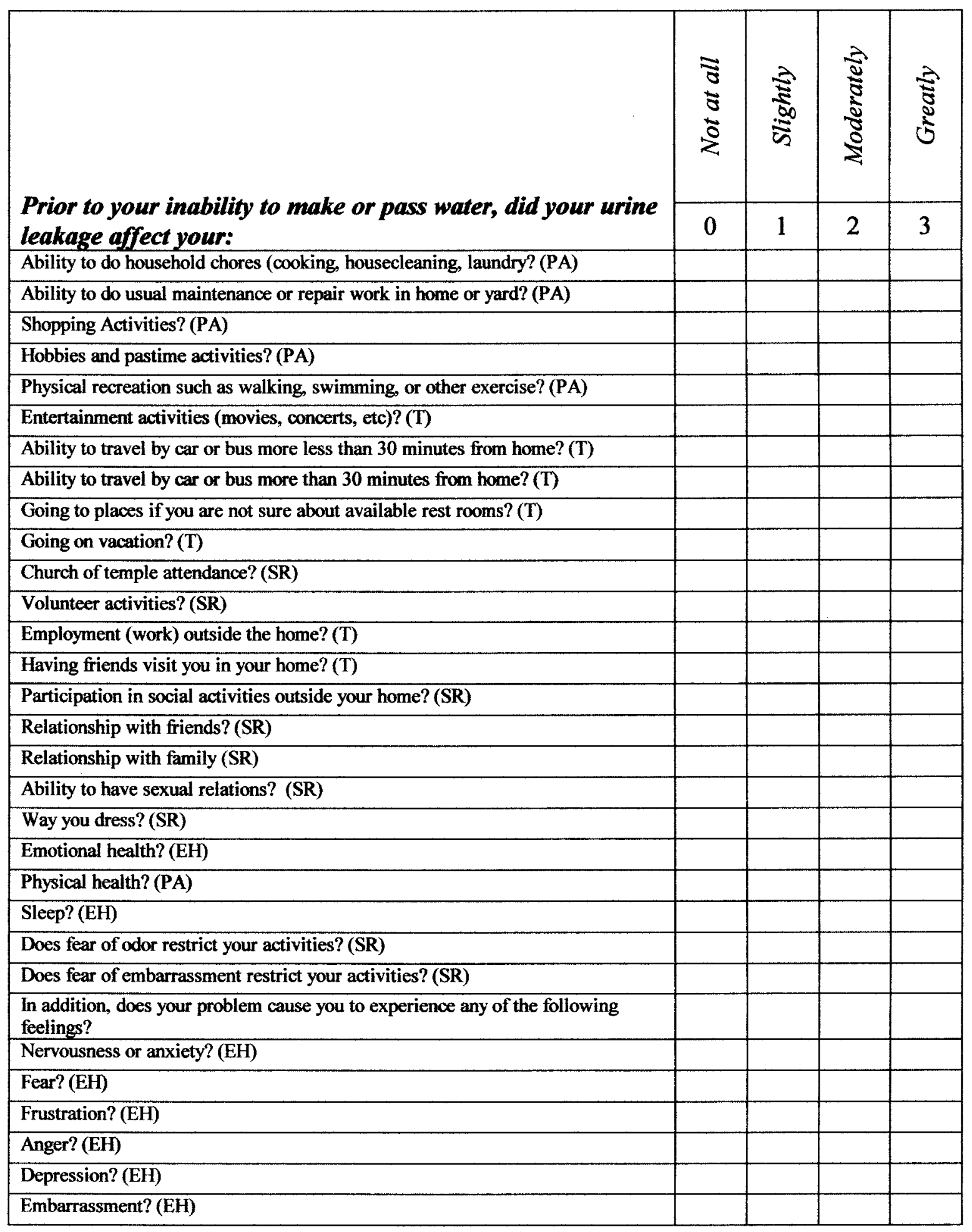




\section{VITA}

The author, Michael Howard Heit, is the son of Marvin and Audrey Heit. He was born on Jul 23, 1962, in Queens, New York. In 1980, he received his high school diploma from Half Hollow Hills High School West in Dix Hills, New York. In 1984, he graduated with honors from State University of New York/Binghamton, with a Bachelor of Science degree in biochemistry. In 1988, he graduated from St. Louis University Medical School with the Degree of Medicine. From 1988-1992, he received residency training in Obstetrics and Gynecology at Washington University Medical Center in St. Louis, MO. From 1992-1994, he received fellowship training in Urogynecology and Reconstructive Pelvic Surgery at Rush-Presbyterian St. Luke's Medical Center in Chicago, IL.

In 1994, he joined the faculty of the Department of Obstetrics and Gynecology at the University of Louisville as an assistant professor and Head of the Section Of Urogynecology And Reconstructive Pelvic Surgery. In July 2001, he will be promoted to associate professor with tenure in the Department of Obstetrics and Gynecology and Head of the Division of Female Pelvic Medicine and Reconstructive Surgery. Today, the Division of Female Pelvic Medicine and Reconstructive Surgery consists of three fulltime physicians, clinical research nurse, and fellows in training. Dr. Heit has received the residency teaching award twice in the last six years 
Dr. Heit is a member of the inaugural class of the University of Louisville's

Clinical Research, Epidemiology, and Statistical Training (CREST) program. 